\title{
A noisy spring: the impact of globally rising underwater sound levels on fish
}

\author{
Hans Slabbekoorn ${ }^{1}$, Niels Bouton ${ }^{2}$, Ilse van Opzeeland ${ }^{3}$, Aukje Coers ${ }^{4}$, Carel ten Cate ${ }^{1}$ \\ and Arthur N. Popper ${ }^{5}$
}

\author{
${ }^{1}$ Behavioural Biology, Institute of Biology, Leiden University, Sylviusweg 72, 2333 BE Leiden, The Netherlands \\ ${ }^{2}$ Evolutionary Ecology Group, University of Antwerp, Groenenborgerlaan 171, B-2020 Antwerp, Belgium \\ ${ }^{3}$ Ocean Acoustics Lab, Alfred Wegener Institute, Am alten Hafen 26, 27568 Bremerhaven, Germany \\ ${ }^{4}$ Pelagic Regional Advisory Council, Treubstraat 17, 2288 EH Rijswijk, The Netherlands \\ ${ }^{5}$ Department of Biology and Center for Comparative and Evolutionary Biology of Hearing, University of Maryland, College Park, \\ MD 20742, USA
}

\begin{abstract}
The underwater environment is filled with biotic and abiotic sounds, many of which can be important for the survival and reproduction of fish. Over the last century, human activities in and near the water have increasingly added artificial sounds to this environment. Very loud sounds of relatively short exposure, such as those produced during pile driving, can harm nearby fish. However, more moderate underwater noises of longer duration, such as those produced by vessels, could potentially impact much larger areas, and involve much larger numbers of fish. Here we call attention to the urgent need to study the role of sound in the lives of fish and to develop a better understanding of the ecological impact of anthropogenic noise.
\end{abstract}

\section{The myth of a silent underwater world}

In 1962, Rachel Carson wrote about a 'silent spring' in the context of the detrimental impact of the use of pesticides on singing birds. Here we call attention to a 'noisy spring', and the possible detrimental impact of increasing levels of anthropogenic noise on fishes ${ }^{1}[1,2]$. Fish populations have come under threat for a number of well-known reasons including fisheries [3], habitat degradation [4] and chemical pollution [5]. Human-generated underwater noise is potentially becoming another threat to fish, just as traffic noise has become a major concern in air with regard to birds and other terrestrial animals [6,7]. Although humans have engaged in all sorts of activities in, on, and near water bodies for a long time, only recently have these activities expanded in an increasingly noisy manner (Box 1). To date, underwater noise pollution has primarily attracted attention in the context of marine mammals [8-10], but it is increasingly recognized as a factor that may also have implications for fish [11-14].

In this review we focus on the need for behavioural and ecological studies on the impact of long-term anthropogenic noise on fishes. We take this approach since very large numbers of fish are exposed to moderate but widespread low-frequency noise, produced by vessels, offshore wind farms and other coastal activities, and yet we have

Corresponding author: Slabbekoorn, $\mathrm{H}$.

(H.W.Slabbekoorn@Biology.LeidenUniv.NL)

${ }^{1}$ Unless otherwise specifically noted, 'fish' in this paper refers to bony fishes of the Osteichthyes taxonomic subclass, the Actinopterygii (or ray-finned fishes).. the barest insight as to the nature and extent of the behavioural impact of such sounds on fishes (Figure 1). While data on fish behavioural responses to the increase in ambient sound are generally not available, we can use data derived from other vertebrates to suggest that anthropogenic noise may deter fish from important feeding and reproduction areas, interrupt critical activities, or cause stress-induced reduction in growth and reproductive output. The concern about wide-ranging effects is further heightened because sound is of critical importance in the lives of many fish species. Impeding the ability of fish to hear biologically relevant sounds might interfere with critical functions such as acoustic communication, predator avoidance and prey detection, and use of the 'acoustic scene' or 'soundscape' $[15,16]$ to learn about the overall environment. Taken together, these potential effects could

\section{Glossary}

Active space: the distance from a sound-emitting animal over which the sound is detectable and recognizable by conspecifics. The active space is influenced by the source amplitude, receiver sensitivity, attenuation and degradation during transmission, and interference by ambient noise.

Anthropogenic noise: any sound generated by human activities, which has the potential to warn fish of the danger of approaching boats or risky water inlets. It may also be detrimental to fish through deterrence, interference and masking of biologically relevant sounds, or through physiological stress.

Auditory detection continuum: mechanistic scale of fish hearing, replacing the traditional and oversimplified categories of generalists and specialists. The scale ranges from fish species without a swim bladder or other air-filled body cavities and only able to detect particle motion (e.g. sharks) to fish species with a so-called otophysic connection between swim bladder and ear and able to detect motion as well as sound pressure (e.g. goldfish).

Auditory masking: the perceptual interference of one sound (often concerning a signal) by another (often referred to as noise). The masking impact occurring at the point of the receiver typically depends on the spectral overlap between and the amplitude ratio of the signal and the noise.

Cortisol: a corticosteroid hormone or glucocorticoid, often referred to as a stress hormone, due to its involvement in response to stress and anxiety. Cortisol serves to increase blood sugar levels, stores sugar in the liver as glycogen, and also suppresses the immune system.

Inner ear: the major structure in fish for detection of sound. The inner ear is located in the cranial cavity of fish and its basic structure is the same as the inner ears of sharks and all terrestrial vertebrates, including humans.

Lateral line system: a sense organ used to detect movement and vibration in fish. Lateral lines are usually visible as faint lines running lengthwise down each side of the body and sometimes as a faint network of dots on the head. Swim bladder: an internal gas-filled organ found in most fish species (but for example not in sharks and rays amongst others) that contributes to the ability to control buoyancy control and allows a fish to stay at a particular water depth. The swim bladder can also serve as a resonating chamber and aid in sound production and sound perception. 


\section{Box 1. Human invasion of the underwater acoustic environment}

Underwater sounds generated by human activities can be subdivided in two categories: sounds that are an unintentional byproduct and sounds that are used as a measurement tool. Dominant in the first category are low-frequency noises from vessels for container shipping, public transport, fishing and recreational activities $[1,2,67,68,88]$. For example, $>80 \%$ of global freight transport takes place over water by motorized shipping, while passenger crossing occurs on many rivers, lakes and seas, often on noisy ferries that shuttle between harbours at frequent intervals. Moreover, fishing vessels typically have strong and noisy motors for towing gear. Although the global fishing fleet has not grown much since the early 1990s it still includes about 1.2 million vessels. The number of recreational vessels is still on the rise, with a growing impact on coastal and in-shore waters $[32,42,89]$. Another significant source of anthropogenic noise of the first category is that associated with construction and exploitation of offshore platforms. The first submerged oil wells were drilled in a fresh water lake in Ohio (USA) around 1891, and five years later, the first marine oil wells were drilled near Santa Barbara, California (USA). Today, there are thousands of offshore oil and gas platforms worldwide. In addition, the more recent development of exploitation of renewable sources, such as wind, wave, tidal or current energy, also generates noise during construction and operational phases [90-92].

The second category of human-generated sounds for various types of underwater measurements involves both low and high frequencies. Underwater sound is used by navies, fisheries, the oil and gas industry, oceanographers, geologists, as well as meteorologists. The first time that sound was used by humans to locate objects underwater was shortly after the Titanic sank in 1912. After that, the use of mid- and later low-frequency sonar has become widespread for navigation and localization of submarines and other objects. In the context of fisheries, the first acoustic study concerned the localization of spawning cod at the Lofoten Islands in 1935 [93]. Then, by 1950 , fish-finding echo sounders had become an essential aid to all commercial fishing vessels. Other acoustic measurement applications include seismic reflection profiling using high-intensity airguns to obtain information about the geological structures beneath the seafloor, and acoustic thermography of ocean climate (ATOC). The second of these was launched in the $1990 \mathrm{~s}$ using relatively high-intensity sound transmission for long periods to determine ocean temperature [9].

have a significant impact on survival of individuals and populations and affect whole ecosystems.

It is important to make three points at the start of this review. First, our emphasis is on behavioural effects of

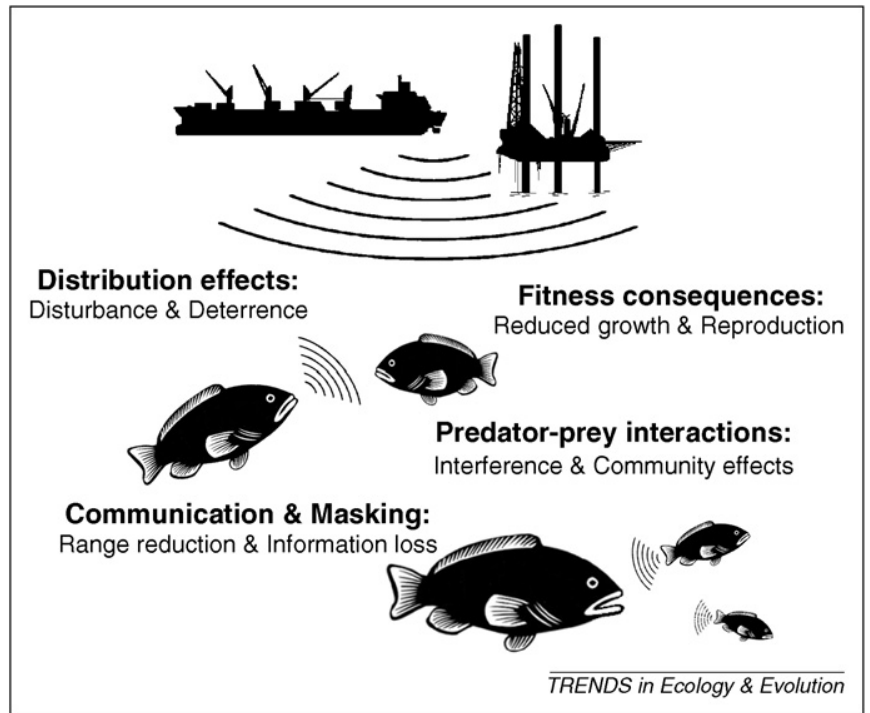

Figure 1. Four main domains of research to assess the potential impact of moderate but widespread anthropogenic noise conditions on fish (see Box 4).

human-generated sounds because these are likely to be the most significant for fish. At the same time we recognize that there is a great concern by many investigators, regulators and various industries about high impact sounds. Underwater explosions, pile driving, or seismic surveys, can all have dramatic effects on nearby fish, including physical damage and death. While not covered here, these immediate effects involving relatively few individual animals have recently been reviewed in great detail [14].

Second, we also emphasize in this review that researchers of the noise impact on fish can get valuable insights from investigations that have been concerned with similar issues in terrestrial animals and, to a lesser extent, marine mammals. In particular, studies on birds might provide guidance in experimental design and in asking questions that are the most useful in gaining a better understanding. Considering the striking similarities in the auditory system and perceptual abilities of all vertebrates [15], it would also not be surprising to find congruencies in the

\section{Box 2. Underwater sound - an overview}

The basic principles of sound propagation in air and in water are the same, but there are a number of features peculiar to underwater acoustics [94,95]. Water is an excellent medium for sound transmission because of its high molecular density. Sound travels about five times faster in water than in air (about 1500 vs. $300 \mathrm{~m} / \mathrm{s}$ ), and this means that wavelengths are about five times longer in water than in air (e.g. for a $100 \mathrm{~Hz}$ signal: $3 \mathrm{~m}$ in air, $15 \mathrm{~m}$ in water). Sound also attenuates less over the same distance in water than in air. As a consequence, sound travels much greater distances at higher amplitude levels in water compared to air, thereby enabling longdistance communication, but also a long-distance impact of noise on aquatic animals.

Sound levels or sound pressure levels (SPL) are referred to in decibels $(\mathrm{dB})$. However, the $\mathrm{dB}$ is not an absolute unit with a physica dimension, but is instead a relative measure of sound pressure with the lower limit of human hearing corresponding to $0 \mathrm{~dB}$ in air Underwater dB-levels are different from above water dB-levels [95]. Sound pressure levels above water are referenced to $20 \mu \mathrm{Pa}$, while underwater they are referenced to $1 \mu \mathrm{Pa}$. As a consequence, adding
$25.5 \mathrm{~dB}$ to the airborne $\mathrm{dB}$-level is required to get a comparable underwater dB-level. Furthermore, related to the much higher acoustic impedance of water compared to air, another $36 \mathrm{~dB}$ correction is required, making an airborne sound pressure level of $70 \mathrm{~dB}$ re $20 \mu \mathrm{Pa}$ comparable to an underwater $131.5 \mathrm{~dB}$ re $1 \mu \mathrm{Pa}$.

Sound pressure levels are based on root-mean-square (RMS) measures averaged over time. They are useful for relatively long sounds but less effective for brief sounds such as pile-driving strikes and echolocation clicks of whales. Peak-to-peak values in the amplitude waveform provide an alternative measure, but comparisons between peak-to-peak and RMS levels are difficult [96]. Recently, investigators have adopted another so-called Sound Exposure Level (SEL), which is an alternative measure reflecting the total acoustic energy received by an organism $[13,14]$. A final issue of critical importance for understanding underwater sound as it relates to fish is the presence of a substantial particle motion component in the aquatic sound field, along with pressure. Since water is so dense, particle motion is a component of the sound field at all distances and fish are adapted to detect this component (see Box 3 ). 
behavioural and physiological impact of human-generated sounds among very different vertebrate groups.

Third, it is important to stress that some fundamental insight into underwater acoustics is critical for a proper understanding of the problem with noise (Box 2). For example, the world of fish has been wrongly assumed to be quiet, as reflected by the title of Jacques Cousteau's 1956 movie The Silent World. The supposition that the underwater world is silent no doubt arose because sound transmission from water to air is poor, and because the air-adapted human ear is a relatively poor receiver underwater. In thinking about underwater acoustics, it is also important to realize that aquatic animals often live in a dark or turbid environment: even a few metres from the animal the use of vision to gather information becomes restricted. In contrast, sound is not restricted by low light levels or objects in the environment, while many aquatic animals, including all fish, have more or less advanced abilities to hear (Box 3).

\section{Are there noise-dependent fish distributions?}

If anthropogenic noise deters fish, or if noise is bad for fish survival and reproduction, one might predict lower fish diversity and density at noisy places. At the moment, however, there are few studies that indicate such negative correlations between the presence of noise and the presence of fish. Some studies report an effect of vessel noise on fish flight behaviour in the context of population assessments and catch rates for commercially important fish stocks. For example, horizontal and vertical movements away from vessels have been reported for Atlantic herring (Clupea harengus) and Atlantic cod (Gadus morhua) $[17,18]$, presumably in response to ship noise. Another example concerns effects of nearby boating noise on blue-fin tuna (Thunnus thynnus) in large oceanic pens. In the presence of boat noise, tuna schools were less coherent than when the noise was not present and individual fish often swam independently towards the surface or the bottom [19]. Fish have also been reported to flee from seismic shooting areas as inferred from decreased catch

\section{Box 3. Fish ears and hearing abilities}

All fish studied to date are able to hear sounds $[15,97,98]$. They have two sensory systems for detection of water motions: the inner ear (there is no outer or middle ear) and the lateral line system. The ear serves to detect sound up to hundreds or even thousands of $\mathrm{Hz}$ (depending on the species), whereas the lateral line detects low-frequency sound (e.g. $<100 \mathrm{~Hz})$, but is generally considered to be primarily a detector of water motion relative to the body.

Sound can be thought of in terms of both particle motion and pressure fluctuations. Sensory hair cells in the inner ear and lateral line (both of which are very similar to those found in the mammalian ear) are stimulated by mechanisms that respond to particle motion and are responsible for converting these motions to electrical signals that stimulate the nervous system. The lateral line system is found along both sides of the body and typically spreads out over the head region where it plays a dominant role in the detection of water motion and low-frequency sound at short distances (one or two body lengths). In contrast, the inner ear also detects sounds of much higher frequencies and from greater distances (probably via acoustic pressure since particle motion declines with distance more rapidly).

Different fish species vary in absolute sensitivity and spectral range of hearing (Figure I), which relates to an auditory detection continuum based on presence or absence of specially evolved morphological structures $[15,97,98]$. Special features that improve the pressure-tomotion transduction from the swim bladder may involve gas-filled cavities reaching the inner ear. There may also be a direct mechanical connection between the swim bladder and the inner ear through a series of bones (the Weberian apparatus) such as in a large group of fish species (Otophysi) that includes goldfish (Carassius auratus) and catfish. Generally speaking, fish hear best within $30-1000 \mathrm{~Hz}$, while species with special adaptations can detect sounds up to 3000 $5000 \mathrm{~Hz}$. Some exceptional species are sensitive to infrasound or ultrasound.

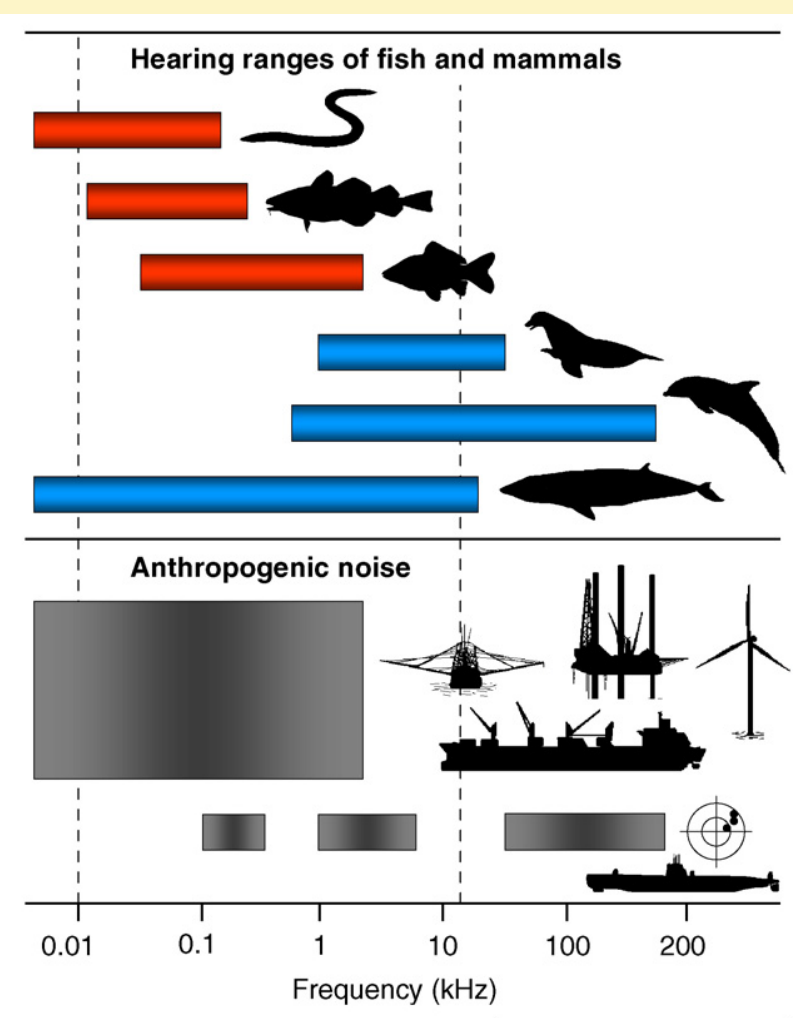

$\overline{T R E N D S}$ in Ecology \& Evolution

Figure I. Hearing ranges of selected fish and mammal species, reflecting some of the typical variety in these taxonomic groups (for reviews see Refs $[10,15])$. The vertical dashed lines demarcate the human hearing range in air. Each species has a more restricted range of peak sensitivity within the species-specific limits (not indicated). From top-to-bottom, red horizontal bars represent: European eel, a freshwater species spawning at sea with sensitivity to infrasound; Atlantic cod, a marine species with 'average' hearing abilities; and goldfish, representing many freshwater fishes with specially evolved hearing abilities. For mammals in blue, we included Californian sea lion (Zalophus californianus), bottlenose dolphin (Tursiops truncatus), and fin whale (Balaenoptera physalus). The anthropogenic noise ranges indicate where the majority of sound sources have most of their energy, although some human-generated sounds exceed these frequencies. At the bottom of the figure are frequency ranges of low-frequency (USA), midfrequency and high-frequency sonar. 
rates for both long lines and trawler fisheries [20,21]. However, there is also a study with direct observations on reef fish that remain close to their territories after exposure to seismic air-gun shooting [22].

In contrast to the little we know about effects of environmental sound on fish behaviour, a good deal is known about the potential impact of anthropogenic noise on bird behaviour. For a long time, declines in avian diversity and density associated with highways have been attributed at least partly to traffic noise [23]. The idea was supported by a study suggesting that a negative effect was dependent on the spectral overlap between traffic noise and birdsong [24] and by several studies showing spectral flexibility in bird species that do well under noisy conditions [6]. However, the best evidence for a negative impact of anthropogenic noise on birds comes from natural areas around extraction stations associated with the gas and oil industry $[25,26]$. Some extraction stations are noisy and others quiet, and this subdivision is independent of the aboveground variation in avian habitat characteristics. Consequently, and in contrast to traditional road-impact studies, the decline in bird breeding density and diversity found in these studies can be attributed solely to the impact of noise.

Whether similar results will be found for fish is not known, but the avian results are highly suggestive of questions that must be asked for fish, and they even suggest ways to explore and answer such questions. For example, it may be possible to investigate the impact of noise on fish diversity and density by making use of the maritime gas and oil industry. Similar to the above water situation with birds, there are offshore platforms that have high underwater noise levels due to compressor noise and human activity, while others serve as more silent satellites. Alternatively, freshwater systems, often being more accessible, can be explored experimentally by using artificial noise sources in some locations that can be compared to quiet, control locations. While data on sound conditions and fish behaviour at these control locations may provide insight into the potential for soundscape orientation $[15,16]$, such an experimental set-up would allow for testing an impact on species community and relative densities dependent on artificial noise levels and specific noise features. The impact of anthropogenic noise on dispersal and passage of migratory fish can be tested in a similar way in canal and river systems $[27,28]$.

\section{Consequences for fish that remain in noisy waters}

Notwithstanding the lack of proper monitoring data, fish sometimes congregate, seeking shelter or food, at places with artificially high noise levels. Anecdotal observations on fish under noisy bridges or near noisy vessels indicate that adverse effects are not necessarily overt and obvious, but they do not tell us whether fish experience any negative consequences related to the noise. For example, several studies in captive fish have shown an increase in secretion of the stress hormone cortisol during exposure to white noise or simulated boat noise [29,30, but see 31]. Other recent studies on potential indicators of stress in captive fish report noise-related rises in heart rate [32] and increased motility related to several blood parameters reflecting increased muscle metabolism [33]. Although one must be cautious in extrapolating to free-swimming fish that may be able to leave areas of high stress, these findings at least suggest that anthropogenic noise could be a stressor in natural water bodies.

Noise-dependent stress, like other environmental stressors, might affect growth and reproductive processes [34], but this has hardly been investigated. A relatively old study, in which the acoustics of the experiments were poorly controlled and calibrated, suggested lower egg viability and reduced larval growth rates in noisy fish tanks compared to more quiet control tanks [35]. A more recent and better study on rainbow trout (Oncorhynchus mykiss), exposed to realistic noise levels for fish tanks in an aquaculture facility [36] showed no impact on growth, survival, or susceptibility to disease, even over nine months of exposure [31]. However, given the very limited number of species investigated, it is not clear whether one can extrapolate from captive rainbow trout to other species that may differ in hearing ability and in the extent they depend on sound for natural activities.

In addition to an impact on growth or reproduction related to noise-determined physiological stress, anthropogenic noise may also affect populations in a more indirect way. Data on birds has shown that individuals that vary in reproductive abilities, related to age, experience, or size, may not be evenly distributed over noisy and quiet areas of otherwise suitable habitat $[37,38]$. The relative absence of more experienced and typically more productive males in noisy territories means that habitat productivity for these species diminished beyond the effect of a reduction in number of territory holders. These results may be relevant to fish since many species are territorial and have explicit age-dependent size classes varying in productivity [39]. However, so far we lack any study looking at distribution of size classes relative to noise levels.

Population productivity of noisy areas might not only be affected by lower numbers or lower-quality individuals, but might also decline due to lowered reproductive efficiency. Data on frogs has shown, for example, that anthropogenic noise may either increase or decrease calling activities $[40,41]$, with possible fitness consequences related to increased energetic or predation costs or decreased mating success. While there are no similar data yet for free-living fish, a relatively old study reports on actual interruption of spawning in roach (Rutilus rutilus) and rudd (Scardinius erythrophthalmus) by an approaching fast-moving powerboat [42]. Although obviously more data are required, it should be realized that the mere presence of fish in noisy waters does not necessarily mean that they are part of a reproductively active population. A better insight can be generated through studies on the impact of anthropogenic noise on the rate and nature of reproductive behaviour and acoustic signalling in free-living fish.

\section{Masking of acoustic communication}

A specific noise impact that could lead to lower reproductive efficiency for fish is masking of communicative sounds. Over 800 species from 109 families are known to produce sounds, while many more are suspected to do so [43-45]. The sounds that fish produce are, in most cases, broadband 
signals with most energy $<500 \mathrm{~Hz}$. Distinct variation in spectral and temporal characteristics can be related to species [46,47], populations [48], and gender [49]. Furthermore, graded variation in pitch and duration can be correlated with size $[47,50,51]$ or seasonal fluctuations in motivation [52]. Such acoustic variation means that sounds can serve as information carriers in acoustic communication among fish $[43,44,53]$. That fish communicate acoustically becomes evident from the contexts in which the sounds are produced, such as during agonistic interaction in territorial fights, when competing for food, or when being attacked by a predator [54-57].

However, the most common context in which fish are known to produce sounds is in spawning aggregations $[58,59]$ and courtship interactions [60,61]. Although often not explicitly demonstrated, sounds could serve in aggregating reproductive groups, in which they may contribute to synchronization of male and female gamete release [62]. At a more individual level, sounds could attract potential mates to a specific place for courtship or egg shedding [63]. Recent experimental evidence has unequivocally shown that sounds can modify mate choice decisions in fish. Female haplochromine cichlids (Pundamilia nyererei) pro- vided with a choice between two males, matched in size and colour, preferred to interact with the male associated with playback of conspecific sounds [47]. An acoustic impact on sexual preferences was also inferred for Atlantic cod in which the male drumming muscle mass was correlated with mating success [64]. Although these examples strongly suggest acoustic communication occurs in fish, there is a substantial lack of insight into the distribution and nature of the phenomenon across species and across habitats (from shallow waters to the deep sea).

Clearly, however, if fish sounds serve a communicative function in a reproductive context, problems of detection and recognition due to the presence of anthropogenic noise [65-67] could have fitness consequences. It should be clear that fish have not evolved in a quiet environment, and natural noise levels can also become loud, for example during fish choruses [58,59]. Nevertheless, playback of field recordings under laboratory conditions, at natural spectral content and level, confirmed experimentally that noise generated by a cabin-cruiser type of boat can significantly increase detection threshold levels for conspecific sounds in both brown meagre drums (Sciaena umbra) and Mediterranean damselfish (Chromis chromis) [68]. Based

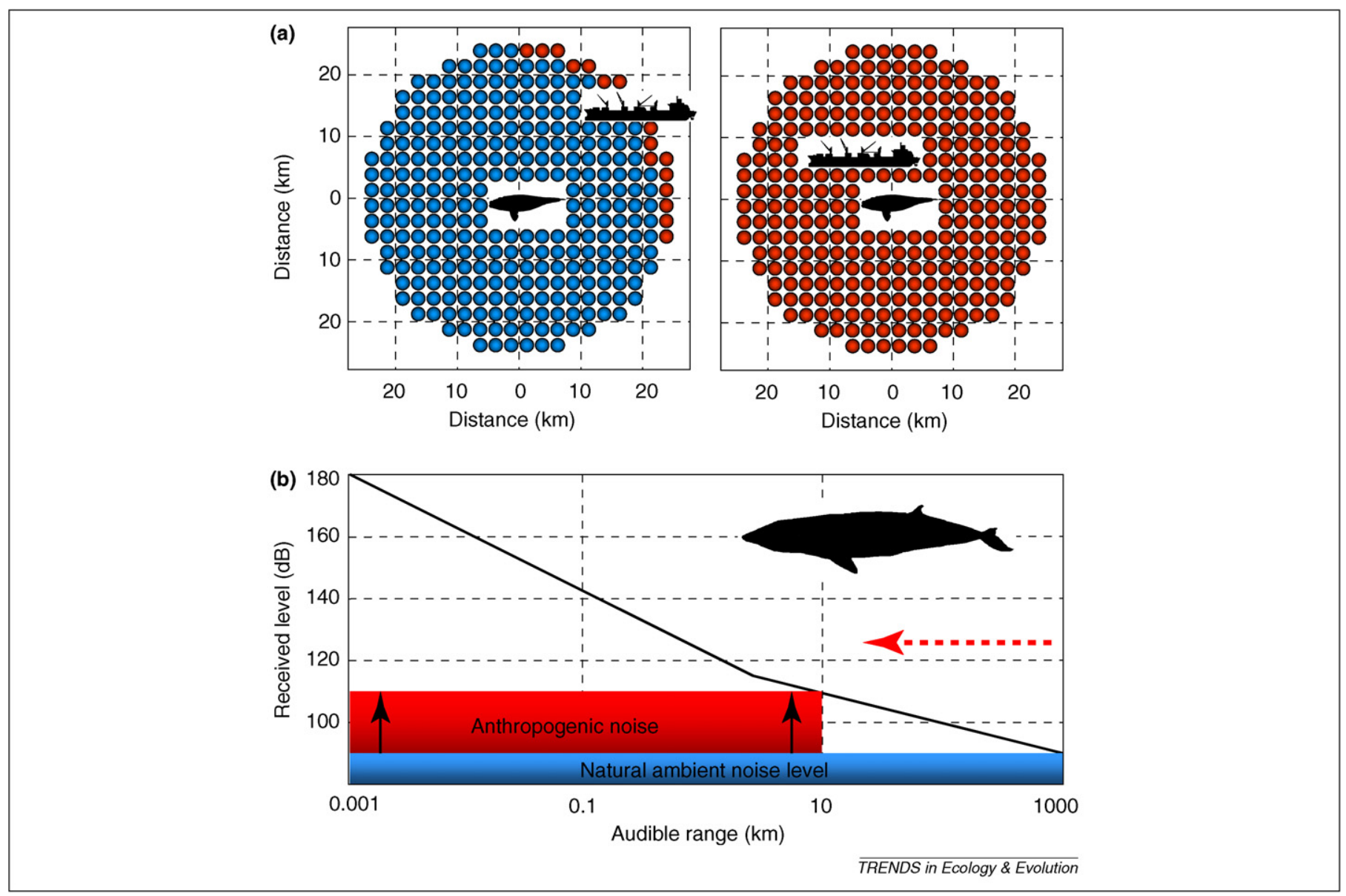

Figure 2. (a) Spatial distribution of sender communication space for uniformly distributed right whales listening to a $200 \mathrm{~Hz}$ conspecific call from a male individual in the centre of the space in the presence of noise from a ship with a source level of $172 \mathrm{~dB}$ re $1 \mu \mathrm{Pa}$. Blue dots indicate receivers for which the whales are likely to detect the sound produced by the focal individual, while red dots indicate receivers for which the noise of the ship exceeds the signal beyond detectable levels. Left: the ship is approaching the calling whale from the northeast causing a $6 \%$ decrease in the sender's communication area. Right: the ship is within $2 \mathrm{~km}$ to the northwest of the caller causing a $97 \%$ decrease in the sender's communication area [87]. (b) Loss of communication range due to a rise in anthropogenic noise relative to historical conditions. Received sound levels for $20 \mathrm{~Hz}$ fin whale calls are depicted against a background of natural noise levels (in blue), yielding an audible range of $1000 \mathrm{~km}$, and elevated noise levels due to anthropogenic influences (in red), leading to a reduced audible range of only $10 \mathrm{~km}$. The graph is modified, with permission, after a model by Peter Tyack. He incorporated realistic signal attenuation during propagation through the ocean in his model and assumed a $90 \mathrm{~dB}$ re $1 \mu$ Pa noise floor for the pre-industrial ocean, currently elevated by $20 \mathrm{~dB}$ from shipping (which is still a conservative estimate likely to be met at many places). 
on these measurements, passing boats were inferred to reduce detection distances under field conditions by up to 100 times.

Masking leading to a reduction in detection distance, or the so-called active space, can lead to failure in mate attraction. Although we lack any empirical evidence demonstrating this for fish, data for birds and frogs can inform our views on the potential for masking effects. Male ovenbirds (Seiurus aurocapillus) near gas extraction stations experienced a decline in mate attraction rates when trying to convey their acoustic message in the presence of a noisy compressor [38]. Another consequence of masking could be that sexual signals are still detected, but that specific acoustic cues in the signals that are important for mate selection get lost. In fish, allometric correlations with acoustic features provide ample opportunity for female mate selection that targets male size [47,50,51]. Although no data are available yet on acoustic preferences of female fish for sounds of large males over sounds of small males, the phenomenon has been tested, confirmed and shown to be noise-level dependent in frogs [69,70]. Typically, large male frogs are acoustically more attractive to females than small ones, but this advantage seems to be lost under noisy conditions [71]. Apparently, noisy conditions can interfere with mate selection, while suboptimal pairing could negatively affect individual reproductive success and thereby affect whole populations.

It is not only essential to assess signal-to-noise threshold levels for an impact of anthropogenic noise on detection and recognition of relevant sounds. We also need insight into the potential scale of impact of such masking effects under natural conditions. Some calculations exist for active space shifts due to anthropogenic noise in frogs [72] and fish [68], and there are some especially insightful studies for marine mammals that may conceptually well apply to fish. For example, baleen whales (Mysticetes) produce low frequency sounds that may travel for hundreds of kilometres, and it has been suggested that these sounds may be used for communication and orientation [73,74]. Figure 2 illustrates at what distances such calls of North Atlantic right whales (Eubalaena glacialis) are still audible in the presence of anthropogenic noise from an approaching ship (a). Data are also shown for fin whales (Balaenoptera physalus) from historical to current ocean noise levels (b). It is important to realize that the active space may also be affected in a similar way for any sound in the auditory scene that may serve as a general orientation cue, for example in making settlement decisions such as suggested to be the case in coral reef fish [75] and crab larvae [76].

\section{Noise-impact on predator-prey relationships}

Hearing and localizing of sounds can also be advantageous for specific purposes such as locating prey and avoiding predators. For example, although sharks and other cartilaginous fishes probably have relatively poor hearing sensitivity compared to other fishes, they were reported to approach irregularly pulsed broadband sounds, which could be indicative for the presence of struggling prey [77]. Similarly, surface-feeding fish can localize prey accurately by listening to the surface waves produced when prey fall into the water [78]. Some bottom-feeding fish such as peacock cichlids (Aulonocara) are even able to sense the sound of prey submerged in the sediment [79]. In other species, broad hearing bandwidths have been correlated with predator avoidance. For example, some herring species (Clupeidae) of the genus Alosa are capable of detecting ultrasound (up to $180 \mathrm{kHz}$ ), which could allow detection and avoidance of echo-locating whales [80,81]. Field studies on European eel (Anguilla anguilla) and juvenile salmonids showed that they are able to detect and avoid infrasound $(<20 \mathrm{~Hz})$, which could allow them to sense the hydrodynamic noise generated by approaching predators [82,83]. Data are completely lacking in fish, but based on insight from very few and very different animal species, we believe that anthropogenic masking effects on predator-prey relationships could be widespread.

Predators that use sound for hunting (as might occur especially in dark or turbid environments) can be restricted by noisy conditions through lower availability of suitable foraging areas and a lower catching efficiency. An instructive mammalian example of this comes from a study on greater mouse-eared bats (Myotis myotis) which use subtle rustling sounds to locate their prey. Captive bats tended to avoid the noisy side of a two-compartment flight room, and also showed lower hunting efficiency when they did enter the noisy compartment [84]. Similarly, prey that use their ears to scan for predators can be negatively affected by anthropogenic noise. In a study on chaffinches (Fringilla coelebs), a species that is potential prey for cats and raptors, foraging birds increased the amount of time that they were upright and scanning visually for predators in high noise conditions compared to when it was quieter and they could listen for predators [85]. This finding was interpreted as a compromise on food intake rate to compensate for finches relying less on auditory detection of approaching predators. In line with this interpretation, a recent study on terrestrial hermit crabs (Coenobita clypeatus) reported a noise-dependent decrease in efficiency with respect to predator detection (represented by a walking person) [86]. These three experimental studies, while not for fish, clearly highlight the potential concerns for the effects of anthropogenic noise on predators as well as prey, and the need for parallel experiments with fish.

\section{Conclusions}

It has become clear that sound can be important to fish and that a rise in artificial noise levels underwater may have negative consequences for individuals as well as populations. Although sonar, piling and explosions typically attract most attention, it is reasonable to argue that the greater impact on fish will be from less intense sounds that are of longer duration and that can potentially affect whole ecosystems. Thus, our goal in this review has been to outline the potential impact of sound in four main areas related to moderate but widespread anthropogenic noise conditions (Box 4). The current lack of insight impedes our ability to make predictions about the effects of anthropogenic noise on fish and we have argued that we could gain such insight using data and methodology from studies on various terrestrial animals. We believe our review strongly suggests that the investigations needed most include those 


\section{Box 4. Major targets for future research}

More field studies are needed on the role of sound in the life of fishes in general, especially with respect to the use of sounds for general orientation purposes (i.e. soundscape orientation $[15,16]$ ). Furthermore, while data are required on the effects of very high intensity, relatively transient sounds as well as on the effects of lower intensity, but more long-term sounds, the greatest impact on most fish clearly comes from the latter sources. Thus, studies of such sounds are most urgently needed. More specifically, the kinds of studies especially needed are those that focus on questions related to whether fish are affected behaviourally or physiologically by the global rise in noise levels or specific anthropogenic sounds and how mitigating measures could help to limit such impact. Insight showing that some species are affected by sounds but others are not, that some sounds are detrimental but others are not, or that noise causes trouble during some periods but not during others, are only some examples of how proper investigations may yield opportunities for mitigation with significant ecological implications at relatively low cost. We therefore advocate more studies in four main domains of research which are likely to provide critical insight into key questions raised in this article:

- Noise-dependent fish distributions. Are there differences in how fish are distributed in quiet and noisy environments, and how might these distributions vary depending on sound source, species, fish age, and other physical and biological factors?

- Reproductive consequences of noisy conditions. Is there a negative influence of anthropogenic noise on reproductive success, by causing physiological stress, by restricting mate finding, or by keeping fish from preferred spawning sites?

- Masking effects on communicative sounds. Does the presence of masking sounds of different types and intensities impact the ability of fish to communicate acoustically or use the acoustic 'soundscape' to learn about the environment?

- Masking effects on predator-prey relationships. Does the presence of masking noise affect the ability of fish to find prey (get food) or detect the presence of predators (become food)?

of noise-dependent distribution and reproduction as well as investigations of masking of sounds used for communication, orientation, or detection of predators and prey. Such studies in the aquatic environment are likely to be an order of magnitude harder than for similar studies in air, for example due to human observers having difficulty in seeing aquatic animals over large areas and localizing sounds underwater. Nevertheless, we expect experimental approaches in the laboratory and in the field to yield critical insights. There is no doubt that this will be a challenging and long-term enterprise, but studies on the impact of pesticides on birds and the conservation measures derived from these have also curbed the prophesy of a 'silent spring' for birds. We believe the investigations we have proposed could do the same for fish, and that these provide a better alternative to waiting to see what happens to fish in the dim future of a more and more 'noisy spring'.

\section{References}

1 Andrew, R.K. et al. (2003) Ocean ambient sound: Comparing the 1960s with the 1990s for a receiver off the Californian coast. Acoust. Res. Lett. Onl. 3, 65-70

2 McDonald, M.A. et al. (2006) Increases in deep ocean ambient noise in the Northeast Pacific west of San Nicolas Island, California. J. Acoust. Soc. Am. 120, 711-718

3 Jackson, J.B.C. et al. (2001) Historical overfishing and the recent collapse of coastal ecosystems. Science 293, 629-638

4 Munday, P.L. (2004) Habitat loss, resource specialization, and extinction on coral reefs. Global Change Biol. 10, 1642-1647
5 van der Oost, R. et al. (2003) Fish bioaccumulation and biomarkers in environmental risk assessment: a review. Environ. Toxicol. Phar. 13, 57-149

6 Slabbekoorn, H. and Ripmeester, E.A.P. (2008) Birdsong and anthropogenic noise: implications and applications for conservation. Mol. Ecol. 17, 72-83

7 Barber, J.R. et al. (2009) The costs of chronic noise exposure for terrestrial organisms. Trends Ecol. Evol. 25, 180-189

8 Richardson, W.J. et al. (1998) Marine Mammals and Noise, Academic Press

9 National Research Council (NRC) (2003) Ocean Noise and Marine Mammals, National Academy Press

10 Southall, B.L. et al. (2007) Marine mammal noise exposure criteria: initial scientific recommendations. Aquatic Mammals 33, 412-522

11 Popper, A.N. et al. (2004) Anthropogenic sound: Effects on the behavior and physiology of fishes. Mar. Tech. Soc. J. 37, 35-40

12 Ladich, F. (2008) Sound communication in fishes and the influence of ambient and anthropogenic noise. Bioacoustics 17, 35-37

13 Popper, A.N. and Hastings, M.C. (2009) The effects of humangenerated sound on fish. Integr. Zool. 4, 43-52

14 Popper, A.N. and Hastings, M.C. (2009) Effects of pile driving and other anthropogenic sounds on fish: Part 1-critical literature review. J. Fish Biol. 75, 455-489

15 Fay, R.R. and Popper, A.N. (2000) Evolution and hearing in vertebrates: The inner ears and processing. Hear. Res. 149, 1-10

16 Slabbekoorn, H. and Bouton, N. (2008) Soundscape orientation: a new field in need of sound investigation. Anim. Behav. 76, e5-e8

17 Vabø, R. et al. (2002) The effect of vessel avoidance of wintering Norwegian spring-spawning herring. Fish. Res. 58, 59-77

18 Handegard, N.O. et al. (2003) Avoidance behavior in cod, Gadus morhua, to a bottom trawling vessel. Aqua. Liv. Res. 16, 265-270

19 Sara, G. et al. (2007) Effect of boat noise on the behaviour of bluefin tuna Thunnus thynnus in the Mediterranean Sea. Mar. Ecol.-Prog. Ser. 331, 243-253

20 Hirst, A.G. and Rodhouse, P.G. (2000) Impacts of geophysical seismic surveying on fishing success. Rev. Fish Biol. Fisheries 10, 113-118

21 Slotte, A. et al. (2004) Acoustic mapping of pelagic fish distribution and abundance in relation to a seismic shooting area off the Norwegian west coast. Fish Res. 67, 143-150

22 Wardle, C.S. et al. (2001) Effects of seismic air guns on marine fish. Cont. Shelf Res. 21, 1005-1027

23 Reijnen, R. and Foppen, R. (2006) Impact of road traffic on breeding bird populations. In The Ecology of Transportation: Managing Mobility for the Environment (Davenport, J. and Davenport, J.L., eds), pp. 255274, Springer-Verlag

24 Rheindt, F.E. (2003) The impact of roads on birds: does song frequency play a role in determining susceptibility to noise pollution? J. Ornithol. 144, 295-306

25 Bayne, E.H. et al. (2008) Impacts of chronic anthropogenic noise from energy-sector activity on abundance of songbirds in the boreal forest. Conserv. Biol. 22, 1186-1193

26 Francis, C.D. et al. (2009) Noise pollution changes avian communities and species interactions. Curr. Biol. 19, 1415-1419

27 Popper, A.N. and Carlson, T.J. (1998) Application of sound and other stimuli to control fish behaviour. Trans. Am. Fish. Soc. 127, 673-707

28 Schilt, C.R. (2006) Developing fish passage and protection at hydropower dams. Appl. Anim. Behav. Sci. 104, 295-325

29 Smith, M.E. et al. (2004) Noise-induced stress response and hearing loss in goldfish (Carassius auratus). J. Exp. Biol. 207, 427-435

30 Wysocki, L.E.et al. (2006) Ship noise and cortisol secretion in European freshwater fishes. Biol. Conserv. 128, 501-508

31 Wysocki, L.E. et al. (2007) Effects of aquaculture production noise on hearing, growth and disease resistance of rainbow trout, Oncorhynchus mykiss. Aquaculture 272, 687-697

32 Graham, A.L. and Cooke, S.J. (2008) The effects of noise disturbance from various recreational boating activities common to inland waters on the cardiac physiology of a freshwater fish, the largemouth bass (Micropterus salmoides). Aquatic Conserv: Mar. Freshw. Ecosyst. 18, 1315-1324

33 Buscaino, G. et al. (2010) Impact of an acoustic stimulus on the motility and blood parameters of European sea bass (Dicentrarchus labrax L.) and gilthead sea bream (Sparus aurata L.). Mar. Environ. Res. 69, 136-142 
34 Pickering, A.D. (1993) Growth and stress in fish production. Aquaculture 111, 51-63

35 Banner, A. and Hyatt, M. (1973) Effects of noise on eggs and larvae of two estuarine fishes. Trans. Am. Fish Soc. 102, 134-136

36 Bart, A.N. et al. (2001) Underwater ambient noise measurements in aquaculture systems: a survey. Aquac. Eng. 25, 99-110

37 Reijnen, R. and Foppen, R. (1994) The effects of car traffic on breeding bird populations in woodland. 1. Evidence of reduced habitat quality for willow warblers (Phylloscopus trochilus) breeding close to a highway. $J$. Appl. Ecol. 31, 85-94

38 Habib, L. et al. (2006) Chronic industrial noise affects pairing success and age structure of ovenbirds Seiurus aurocapilla. J. Appl. Ecol. 44, 176-184

39 Savage, V.M. et al. (2004) Effects of body size and temperature on population growth. Am. Nat. 163, 429-441

40 Sun, J.W.C. and Narins, P.A. (2005) Anthropogenic sounds differentially affect amphibian call rate. Biol. Conserv. 121, 419-427

41 Kaiser, K. and Hammers, J.L. (2009) The effect of anthropogenic noise on male advertisement call rate in the neotropical treefrog, Dendropsophus triangulum. Behaviour 146, 1053-1069

42 Boussard, A. (1981) The reactions of roach (Rutilus rutilus) and rudd (Scardinius erythrophthalmus) to noises produced by high speed boating. In Proceedings of the 2nd British Freshwater Fisheries Conference, pp. 188-200

43 Tavolga, W.N. (1971) Sound production and detection. In Fish Physiology, Vol. V (Hoar, W.S. and Randall, D.J., eds), pp. 135-205, Academic Press

44 Ladich, F. (2004) Sound production and acoustic communication. In The Senses of Fish: Adaptations for the Reception of Natural Stimuli (von der Emde et al., eds),pp. 210-230, Kluwer Academic Publishers \& Narosa Publishing House

45 Kasumyan, A.O. (2008) Sound and sound production in fishes. $J$. Ichthyol. 11, 981-1030

46 Kihslinger, R.L. and Klimley, A.P. (2002) Species identity and the temporal characteristics of fish acoustic signals. J. Comp. Psychol. 116, 210-214

47 Verzijden, M.N. et al. (2010) Sounds of male Lake Victoria cichlids vary within and between species and affect female mate preferences. Behav. Ecol. 21, 548-555

48 Parmentier, E. et al. (2005) Geographical variation in sound production in the anemonefish Amphiprion akallopisos. Proc. Biol. Sci. 272, 16971703

49 Ueng, J.P. et al. (2007) Sexual differences in the spawning sounds of the Japanese croaker Argyrosomus japonicus (Sciaenidae). Zool. Stud. 46, 103-110

50 Myrberg, A.A. et al. (1993) The sound of bicolor damselfish (Pomacentrus partitus) - predictors of body size and a spectral basis for individual recognition and assessment. J. Acoust. Soc. Am. 9, 30673070

51 de Jong, K. et al. (2007) Azorean rock-pool blennies produce size-dependent calls in a courtship context. Anim. Behav. 74, 12851292

52 Maruska, K.P. and Mensinger, A.F. (2009) Acoustic characteristics and variations in grunt vocalizations in the oyster toadfish Opsanus tau. Environ. Biol. Fishes 84, 325-337

53 Myrberg, A.A. (1981) Sound communication and interception in fishes. In Hearing and Sound Communication in Fishes (Tavolga, W.N. et al., eds), pp. 395-426, Springer-Verlag

54 Amorim, M.C.P. and Neves, A.S.M. (2008) Male painted gobies vocalise to defend territories. Behaviour 145, 1065-1083

55 Myrberg, A.A. (1997) Sound production by a coral reef fish (Pomacentrus partitus): evidence for a vocal territorial "keep-out" signal. Bull. Mar. Sci. 60, 1017-1025

56 Wilson, B. et al. (2004) Pacific and Atlantic herring produce burst pulse sound. Proc. R. Soc. B-Biol. Sci. 271, s95-s97

57 Wisenden, B.D. et al. (2008) Sound the alarm: learned association of predation risk with novel auditory stimuli by fathead minnows (Pimephales promelas) and glowlight tetras (Hemigrammus erythrozonus) after single simultaneous pairings with conspecific chemical alarm cues. Environ. Biol. Fishes 81, 141-147

58 Saucier, M.H. and Baltz, D.M. (1993) Spawning site selection by spotted seatrout, Cynoscion nebulosus, and black drum, Pogonias cromis, in Louisiana. Environ. Biol. Fishes 36, 257-272
59 Aalbers, S.A. (2008) Seasonal, diel, and lunar spawning periodicities and associated sound production of white seabass (Atractoscion nobilis). Fishery Bull. 106, 143-151

60 Myrberg, A.A. et al. (1986) Sound production by males of a coral reef fish (Pomacentrus partitus): its significance to females. Anim. Behav. 34, 913-923

61 McKibben, J.R. and Bass, A.H. (1998) Behavioral assessment of acoustic parameters relevant to signal recognition and preference in a vocal fish. J. Acoust. Soc. Am. 104, 3520-3533

62 Myrberg, A.A. and Lugli, M. (2006) Reproductive behavior and acoustical interactions. In Communication in Fish (Ladich et al., eds), pp. 149-176, Science Publishers

63 Rollo, A. et al. (2006) Attraction and localization of round goby (Neogobius melanostomus) to conspecific calls. Behaviour 144, 1-21

64 Rowe, S. et al. (2008) Morphological and behavioural correlates of reproductive success in Atlantic cod Gadus morhua. Mar. Ecol.Prog. Ser. 354, 257-265

65 Brumm, H. and Slabbekoorn, H. (2005) Acoustic communication in noise. Adv. Stud. Behav. 35, 151-209

66 Wysocki, L.E. and Ladich, F. (2005) Hearing in fishes under noise conditions. JARO-J. Assoc. Res. Oto. 6, 28-36

67 Vasconcelos, R.O. et al. (2007) Effects of ship noise on the communication signals in the Lusitanian toadfish. J. Exp. Biol. 210, 2104-2112

68 Codarin, A. et al. (2009) Effects of ambient and boat noise on hearing and communication in three fish species living in a marine protected area (Miramare, Italy). Mar. Pollut. Bull. 58, 1880-1887

69 Schwartz, J.J. (1993) Male calling behavior, female discrimination and acoustic interference in the neotropical treefrog Hyla microcephala under realistic acoustic conditions. Behav. Ecol. Sociobiol. 32, 401-414

70 Marquez, R. and Bosch, J. (1997) Female preference in complex acoustical environments in the midwife toads Alytes obstetricans and Alytes cisternasii. Behav. Ecol. 8, 588-594

71 Wollerman, L. and Wiley, R.H. (2002) Background noise from a natural chorus alters female discrimination of male calls in a neotropical frog. Anim. Behav. 63, 15-22

72 Parris, K.M. et al. (2009) Frogs call at a higher pitch in traffic noise. Ecol. Soc. 14, 25

73 Stafford, K.M. et al. (1998) Long-range acoustic detection and localization of blue whale calls in the north-east Pacific. J. Acoust. Soc. Am. 104, 3616-3625

74 Clark, C.W. and Ellison, W.T. (2004) Potential use of low-frequency sound by baleen whales for probing the environment: Evidence from models and empirical measurements. In Echolocation in Bats and Dolphins (Thomas, J.A. et al., eds), pp. 564-581, University of Chicago Press

75 Simpson, S.D. et al. (2005) Homeward sound. Science 308, 221

76 Stanley, J.A. et al. (2010) Induction of settlement in crab megalopae by ambient underwater reef sound. Behav. Ecol. 21, 113-120

77 Myrberg, A.A. (2001) The acoustical biology of elasmobranchs. Environ. Biol. Fishes 60, 31-45

78 Hoin-Radkovsky, I. et al. (1984) Determination of source distance in the surface feeding fish Pantodon buchholzi Pantodontidae. Anim. Behav. $32,840-851$

79 Konings, A. (2001) Malawi Cichlids in their Natural Habitat, Cichlid Press

80 Popper, A.N. et al. (2004) Response of clupeid fish to ultrasound: a review. ICES - J. Mar. Sci. 61, 1057-1061

81 Dokseater, L. et al. (2009) Behavioral responses of herring (Clupea harengus) to 1-2 and 6-7 kHz sonar signals and killer whale feeding sounds. J. Acoust. Soc. Am. 125, 554-564

82 Sand, O. et al. (2000) Avoidance responses to infrasound in downstream migrating European silver eels, Anguilla anguilla. Environ. Biol. Fishes 57, 327-336

83 Knudsen, F.R. et al. (1997) Infrasound produces flight and avoidance response in Pacific juvenile salmonids. J. Fish Biol. 51, 824-829

84 Schaub, A. et al. (2008) Foraging bats avoid noise. J. Exp. Biol. 211, 3174-3180

85 Quinn, J.L. et al. (2006) Noise, predation risk compensation and vigilance in the chaffinch Fringilla coelebs. J. Avian Biol. 37, 601-608

86 Chan, AAY-H. et al. (2010) Anthropogenic noise affects risk assessment and attention: the distracted prey hypothesis. Biol. Lett. U. K. DOI: 10.1098/rsbl.2009.1081 
87 Clark, C.W. et al. (2009) Acoustic masking in marine ecosystems: intuitions, analysis and implications. Mar. Ecol.-Prog. Ser. 395, 201-222

88 Hatch, L. et al. (2008) Characterising the relative contributions of large vessels to total ocean noise fields: a case study using the Gerry E Studds Stellwagen Bank National Marine Sanctuary. Environ. Manag. 42, 735-752

89 Amoser, S. et al. (2004) Noise emission during the first powerboat race in an Alpine lake and potential impact on fish communities. J. Acoust. Soc. Am. 116, 3789-3797

90 Wahlberg, M. and Westerberg, H. (2005) Hearing in fish and their reactions to sounds from offshore windfarms. Mar. Ecol.-Prog. Ser. 288, 295-309

91 de Jong, C.A.F. et al. (2008) Underwater radiated noise due to the piling for the Q7 Offshore Windpark. Proc. ECUA 2008 (Acoustics'08) pp. $117-122$
92 Kikuchi, R. (2010) Risk formulation for the sonic effects of offshore wind farms on fish in the EU region. Mar. Pollut. Bull. 60, 172-177

93 Sund, O. (1935) Echo sounding in fishery research. Nature 135, 953

94 Chapman, D.M.F. and Ellis, D.D. (1998) The elusive decibel: thoughts on sonar and marine mammals. Canadian Acoustics 26, 29-31

95 Finfer, D.C. et al. (2008) Issues relating to the use of 61.5 conversion factor when comparing airborne and underwater anthropogenic noise levels. Appl. Acoust. 69, 464-471

96 Madsen, R.T. (2005) Marine mammals and noise: Problems with root mean square sound pressure levels for transients. J. Acoust. Soc. Am. $117,3952-3957$

97 Kasumyan, A.O. (2005) Structure and function of the auditory system in fishes. J. Ichthyol. 45, S223-S270

98 Popper, A.N. and Fay, R.R. (2010) Rethinking sound detection by fishes. Hear. Res. DOI: 10.1016/j.heares.2009.12.023 